\title{
Research on the Extraction and Visualization of Automobile Brand Form Gene Based on Multi-roles' Expectation Image
}

\author{
Weifeng $\mathrm{Hu}^{1,2, *}$, Xiangyang $\mathrm{Xin}^{1}$, and Binbin $\mathrm{Li}^{1}$ \\ ${ }^{1}$ School of Design, Jiangnan University, Wuxi, China \\ ${ }^{2}$ State Key Laboratory of Advanced Design and Manufacture for Automobile Body, \\ Hunan University, Changsha, China \\ hwf1979@163.com
}

\begin{abstract}
The extraction and visualization of automobile brand form gene based on multi-roles' expectation image was studied from the brand form feature and brand semantic feature two aspects. Using the protocol analysis, interview method and sketch analysis, the automobile brand form genes were extracted from users, automobile form designers and enterprise related personnel. Then the automobile brand form genes were visualized and quantitative described through the Bezier splines, mood board and semantic differential method. Finally, taking the Kia automobile as an example, the method was proved to be rational and feasible.
\end{abstract}

Keywords: Automobile styling, Brand Form Gene, multi-roles' Expectation Image, Visualization.

\section{Introduction}

With the market competition and anabatic technological homogeneity, brand has already been separated from the "trademark" function that is for product differentiation and become a powerful weapon of enterprise competition. As the bridge between enterprise and consumer, product is the important express of enterprise brand image, which accurately reflect the meaning of brand. As to some famous transnational corporations, their product form could maintain good brand recognition in spite of the frequent change of product. Thus, these products could enjoy market supremacy. Though many Chinese enterprises have been aware of the importance of brand, they generally focused on brand awareness, but not the build of product brand image. As a result, their products, especially automobile, lack distinct brand identity and enough competitive power in market [1,2].

Product brand form gene has gradually become an important research area in the study of product design and enterprise brand image. In the world, some researches obtained the brand form genes and studied their continuity based on Shape Grammar,

\footnotetext{
${ }^{*}$ Corresponding author.
} 
Product Semantics, cognitive psychology, Visual decomposition and so on. Interiorly, some researchers studied the extraction and visualization of brand form gene, heredity and variation, evolutionary trend and so on. However, some questions were arose in these researches as following: (1) lack the researches about the relationship between product brand form gene and relative roles such as consumer, relevant personnel of enterprises, designer and so on. That is mean we can not express the correlation between product brand gene and people's emotion, aesthetic and value. (2) Most of the current researches are focused on visual character and have no enough attention on brand image based on semantics. Besides, we can not efficiently visualization of product brand form gene. Therefore, this study put forward a method of extraction and visualization of automobile brand form gene based on multi-role's exception image.

\section{Product Brand Form Gene}

Gene is the nucleic acid fragment containing specific genetic function. Through gene recombination and mutation, organisms continuously evolution and then obtain the stronger ability to adapt to the external environment. The similar idea of evolution is also existed in product form design. Product form gene constantly interacts with design scenario or product environment, which result in the evolution of product to proper form. The repeated application of "basic form" during the process of form evolution was the same as genetic and these basic forms are considered as vocabulary of design elements. The expression of genetic characteristics of vocabulary of design elements is product form gene. Brand form genes are ones closely related with product brand. They are defined as the expression of minimum knowledge granularity of unique characteristics about brand impression. Brand form gene constantly changed along with time and product variation. The brand image is gradually formed through continuously emphasized and repeated of some product brand form genes in different time and on different product form $[3,4,5]$. For example, automobile form includes lamp, grille, side profile and so on. The continuously strengthened and repeated application of shield grille and round asymmetric vehicle logo in different time and on different automobile form result in the formation of unique brand image of Alfa Romeo (Fig. 1) [6].
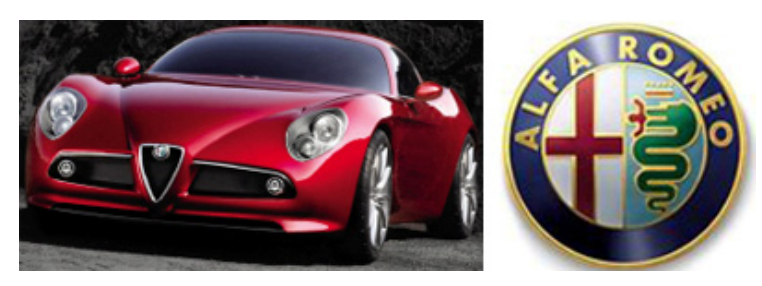

Fig. 1. Brand form gene of Alfa Romeo automobile 
Brand form feature is defined as the form feature that correlated with brand and it is the visible entities of brand form gene. Automobile brand form feature is the assemblage of many specific Automobile form characteristics that accumulated for a long time in Automobile enterprise. These characteristics include the unique form elements about brand and their evolution process. The extraction of Automobile brand form feature is the collation and mining of enterprise brand and the process of systematically cognitive enterprise brand. Automobile brand form feature can be separated into brand form feature dots, brand form feature lines, brand form feature surfaces. As to the expression of form, though dots are important, they are not plenitudinous. Though surfaces can express all contents of form, they are too complex to express. Lines are origin from dots and can compose surfaces, thus brand form feature lines are proper objects to study brand form feature [7].

The transfer of product brand image is not only through product form, but also through the semantic description and emotional cognition. Semantic has rich connotation and a large amount of information. If they are extracted from different conditions, the information are much more broad. Some semantic features are used to describe the connotation of the brand and highlight the characteristics of the brand. They are defined as semantic features. Automobile brand semantic feature is the Automobile enterprises' core values, the unique brand concept and feature and sublimation of enterprise culture. In this study, brand semantic feature is expressed by semantic vocabulary.

As the product brand cognitive method, brand semantic features and brand from features are correlated. Through the combination of automobile brand form and semantic features, their extraction and expression is very important to automobile brand form management and can provide brand form standard for automobile form innovation and differential design. Finally their extraction and expression is useful to establish automobile form brand spectrum management system.

\section{Extraction of Brand Form Gene}

\subsection{Extraction of Automobile Brand Form Feature}

Extraction of automobile brand form feature can provide original data for automobile brand management system establishment. The analysis and refine of brand form feature for main products belong to the same brand is the expression process through standard graphic for brand form elements. Due to the differences of cognition of different roles for product brand features, it's necessary to extract the product brand form feature based on multi-role.

Designers focus on professional analysis of automobile form design. They extract automobile brand form feature based on their expertise including cognitive experiment, protocol analysis [8] and so on. During the experiment, designers are required to report their analysis and thinking process according to the characteristics and requirements of the problem when they are designing the automobile form. The researchers will record and videotape these oral reports and then detailedly analyze them to obtain the information on designers' cognitive activity. 
The related roles in enterprise mainly include enterprise managers and salesman. They have different understanding and describing on enterprise culture, brand concept and product positioning. The extraction of brand form feature of these people should use interview and sketch analysis method.

The preference and view of consumers on product form directly determine the competition ability of product in market. Therefore, the extraction and expression of product brand form gene must pay full attention to consumers. The extraction of automobile brand form feature based on consumers is mainly through questionnaire survey.

\subsection{Extraction of Automobile Brand Semantic Feature}

Form semantic feature is always expressed through language description [9]. In this study, the extraction of automobile brand semantic feature from the following aspects: linguistics, user, enterprise and designer (Fig. 2).

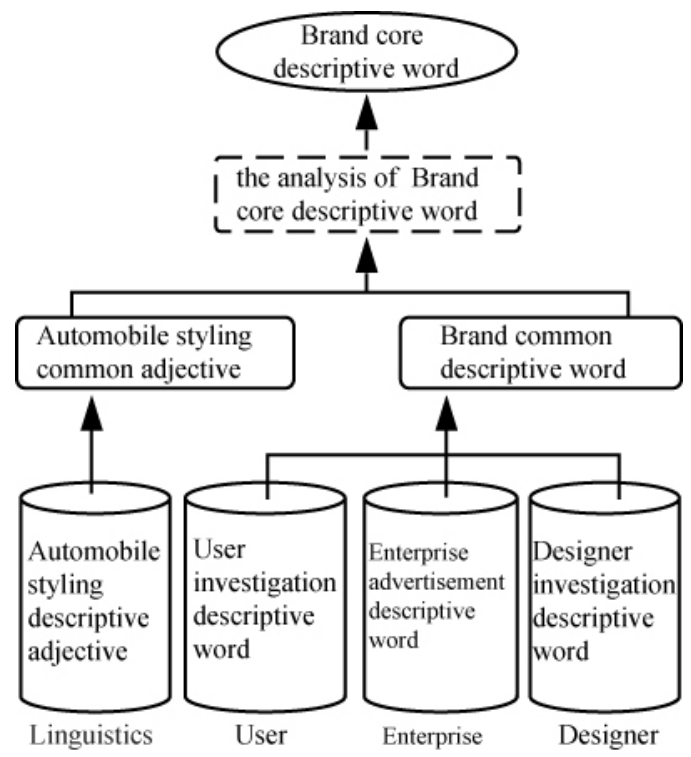

Fig. 2. Process of extracting product brand semantic feature

Linguistics: The adjective words are obtained through literature survey based on Osgood' Semantic Differential Method. The etymology is generally required wide enough to ensure comprehensively sample in the domain semantic space. Then through a series of filter mechanisms, those redundancy and repeated adjectives information in semantic space are cut and filtered. Finally, through the survey of enterprise related people, designers and consumers, the proper adjectives to describe Automobile form are obtained. 
User: the practical and open questionnaire survey that carried on typical user will guide them describe the knowledge and experience about product brand, evaluation and recommendations on product form, the use experience and so on. Then through a series of frequency statistics, the brand semantic description vocabularies are obtained.

Enterprise: Through the interview of enterprise managers, salesman and so on, the understanding and experience of enterprise on brand semantic feature are obtained. In addition, the advertising languages of product should also be studied to obtain the relative brand semantic feature.

Designer: A number of designers with more than five years of automobile design experience are selected to carry out experts' interview and focus group discussion. Then through a series of statistic analysis, the brand semantic vocabularies based on designer are obtained.

\section{$4 \quad$ Visualization of Brand Form Gene}

Visual information and language information plays similar important role in identifying and remember product form. Combine these information and make consumer having stable memory form of product brand gene will greatly improve the cognitive efficiency of automobile brand form. Therefore, it's necessary to visualization of brand form gene.

\subsection{Visualization of Brand Form Feature}

In this study the visualization of brand form feature is carried out through the geometrical description of form feature lines. Because the automobile brand form feature lines are always free curves, the geometrical description can be summarized into several continuous segments 1 and their positions and attribute relationships. For example, automobile profile (E1E2E3) can be expressed as:

$$
E_{1} E_{2} E_{3}=\{l(1,2), 1(2,3), \ldots, l(\mathrm{n}, 1)\}
$$

The segment 1 can be expressed by the anchor point $\mathrm{p}$ and control point $\mathrm{c}$ of this curve. As following:

$$
l(i, j)=\left(p_{i}, p_{i}, c_{i, j}\right)
$$

Because of most automobile form feature lines are smooth, so the form feature lines could be fitted through the Bezier Splines' construction and transformed into feature lines genotypes composed of the feature points' coordinates. The expression of Bezier Splines as following:

$$
\mathrm{B}(t)=(1-\mathrm{t})^{2} P_{0}+2 t(1-t) P_{1}+t^{2} P_{2}, t \in[0,1]
$$

Taking the side profile (E1, E2, E3) as an example, the gene elements of form feature lines are divided into two sorts: anchor point (marked with $\mathrm{P}_{i}, i=1,2 \ldots \mathrm{n}$ ) and control point (marked with $\mathrm{C}_{i}, i=1,2 \ldots \mathrm{n}$ ). The side profile genotypes are expressed through the combination of two gene elements (Fig. 3). 


\subsection{Visualization of Brand Semantic Feature}

The visualization of brand semantic feature focuses on the scenario visualization of vocabulary and the establishment of semantic space.

The brand semantic adjectives are reflected on a psychological scale through Osgood semantic differential method. Then the brand semantic space is established and it is accurately location. Figure 4 shows the 7 points scale of brand semantic adjective "simple-complex". The adjective is divided into seven grades and the each grade is value assignment.

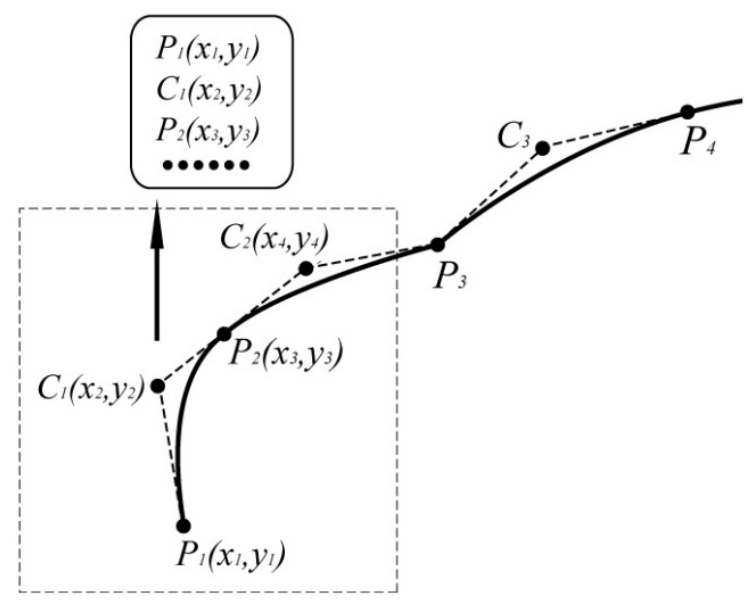

Fig. 3. Side profile (E1, E2, E3) and its expression of Bezier Splines

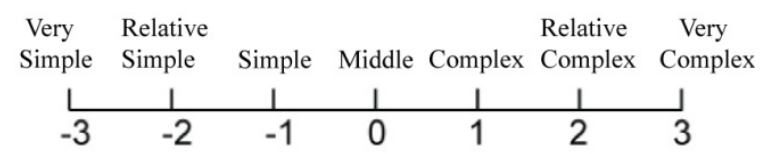

Fig. 4. 7 points scale of brand semantic adjective "simple-complex"

Semantic expression refers to the language description of objects in specific condition and environment. Out of scenario, the rich of semantics will result in the fuzzy and uncertain of describing objects. The establishment of proper scenario will guide the process of design. The Mood Board is usually used to establish the scenario. In this study, as a tool of semantic feature visualization, the Mood Board is adopted to establish the brand visual scenario space.

\section{$5 \quad$ Case Study}

Taking Kia as an example, the brand form genes were extracted and visualized in this study. 


\subsection{Extraction of Kia Brand Form Feature}

During the extraction of Kia feature lines, the expert samples were used to reduce the sample volume and obtain more effective data. In this study, seven designers who have more than five years experience in industrial design and participated in at least one actual automobile design project were selected to extract and analyze the features of four main automobiles of Kia (K2, K5, K7 and Sportage-R).

The First Phase: The automobiles were expressed through sketches which should be accurate and the number was not limited.

The Second Phase: Designers began to carry out the concept design according to the demand of Kia automobile. These concept designs were expressed through sketches that should be clearly enough to reflect the design concept. The main descriptions of design concept should be noted and explained on the sketches.

The Last Phase: Designers were demanded to extract the brand form feature lines according to the sketches draw in the above two phases (Fig. 5)

\begin{tabular}{|c|c|c|c|c|c|}
\hline Vehicle type & \multicolumn{5}{|c|}{ KIA Automobile } \\
\hline Feature & K2 & K5 & K7 & Sportage-R & \\
\hline $\begin{array}{l}\text { Automobile Grille } \\
\text { Outline }\end{array}$ & $\longrightarrow$ & $\square$ & 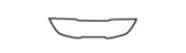 & 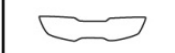 & the core brand features \\
\hline Headlamp Outline & $\square$ & $\otimes$ & $\triangle$ & 0 & the core brand features \\
\hline Taillamp Outline & $\infty$ & $\infty$ & $\square$ & $\infty$ & the core brand features \\
\hline Foglamp Outline & & 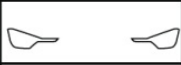 & $\infty$ & $\bowtie$ & $\begin{array}{l}\text { the important brand } \\
\text { features }\end{array}$ \\
\hline $\begin{array}{l}\text { Relationship of } \\
\text { Headlamp and Grille }\end{array}$ & $\checkmark r$ & $\nabla=r$ & $\Delta \rightleftharpoons \triangle$ & $\Delta=0$ & $\begin{array}{l}\text { the important brand } \\
\text { features }\end{array}$ \\
\hline $\begin{array}{l}\text { Automobile Side } \\
\text { Outline }\end{array}$ & & & & & $\begin{array}{l}\text { the important brand } \\
\text { features }\end{array}$ \\
\hline
\end{tabular}

Fig. 5. Extraction of some brand form feature lines of Kia automobile

Because designers have deep understanding on automobile form, the feature lines extracted by them would be highly summarized and accurate. Then the data loss would be small during the automobile form transform. However, due to the lack of deep understanding of automobile brand and market location, these feature lines extracted by designers were one-sided. Thus, enterprise related people and consumers all should participate in the extraction. In this study, 15 staff (managers and salesman) from Kia and 30 users were selected to participate in this experiment through interview and sketch analysis method. The content of interview include: (1) the brand image of Kia; (2) the brand planning and location of Kia. The content of sketch analysis include: (1) find the most marked and continuous form features on the sketches; (2) find the form elements that could reflect the brand form feature of Kia; (2) summarize the change trend of Kia automobile form. 
Based on the above experiments' results, the brand form features of Kia automobile could be summarized as follows: the whole vehicle body is smooth, slightly hale and full of change; the "tiger growl" form of grille; the grille and headlamp shape are matched that reflect the meaning of bird fly.

Through analysis the core brand features of Kia automobile were separated into: (1) the "tiger growl" feature of grille; (2) the sharp feature of headlamp and taillamp. The important brand features include: (1) the overall body feature is smooth, slightly hale and full of change; (2) the grille and headlamp shape are matched that reflect the meaning of bird fly; (3) the "water ladle" form of foglamp (Fig. 5).

\subsection{Extraction of Kia Automobile Brand Semantic Feature}

Linguistics: Thirty objectives generally used to descript Automobile form extracted by State Key Laboratory of Advanced Design and Manufacture for automobile Body in Hunan university were selected as the semantic pool[10].

User: The surveys were carried out on thirty users of Kia automobile to obtain their description of brand semantic feature of Kia automobile. These descriptions were further recognized and recorded as electronic document and the descript objects were noted to help the following statistics.

Enterprise: According to the interview results of enterprise managers and salesman, the analysis of review of Kia automobile and TV advertising language, the Kia brand descript adjectives were extracted.

Designer: Through the interview of seven experts, the Kia brand was described. Then the word frequency statistics and cluster analysis were carried out to obtain the key semantic adjectives on Kia brand.

After the above extraction work, the three levels of Kia brand semantic features and their corresponding adjectives are summarized as following:

Key adjectives (2): cool, athletic

Brand adjectives (3): generous, hale, fluency;

Common adjectives (18): strict-loose, stable-movement, rational-perceptual, roughexquisite, straight-curved, concrete-abstract, simple-luxury, unified- opposite, hardsoft, commercial-leisure, conservative-faddish, porcelain-impolite, elegant- luxuriant, complex-simple, friendly- aggressive, decent-delicate, harmonious- contradictory, biting-gentle.

Using design Mood Board, the semantic adjectives was transformed into the visualized tool aiding brand design management. In the core semantic Mood Board, the key semantic words and the synonyms were correlated, the concept of adjectives were explained, and the related pictures were insert to form semantic situations space. In addition, the corresponding brand form features of semantic features were also list and described in order to assist the following form design and brand management.The situations expression of common adjectives is actually a scaling relation of form image in automobile form design practice. Therefore, in the construction of the semantic Mood Board, the addition of psychological scale of semantic adjectives more accurately aided designers locate the brand form semantic space. 


\section{Conclusion}

In the present study, the concept of product brand form gene was introduced and the extraction and visualization of automobile brand form gene based on multi-roles' expectation image were developed. In the case of Kia automobile, the method was proved to be feasible and reasonable, which would help designers more accurately locating the brand form semantic space.

Acknowledgements. This work was financially supported by the National Social Science Fund (12BG055), the open research fund program of the state key laboratory of advanced design and manufacturing for vehicle body (31115018), Ministry of Education in China project of humanities and social sciences (11YJCZH063) and the Fundamental Research Funds for the Central Universities (JUSRP11246).

\section{References}

1. Yang, Y., Lei, T., Pan, Y.: Product identity, a new method in user-centered design acitivty. China Mechanical Engineering 17, 1105-1109 (2006) (in Chinese)

2. McCormack, J.P., Cagan, J.: Speaking the Buick language: capturing, understanding,and exploring brand identity with shape grammars. Design Studies 25, 1-29 (2004)

3. Yang, Y., Zhang, Y.: Research on Personalized Form Design Based on Product Brand Characteristics Family. China Mechanical Engineering 20, 460-466 (2009) (in Chinese)

4. Zhang, W., Zhao, J.: Study on Audi Brand Form Gene. Packaging Engineering 28, 84-86 (2007) (in Chinese)

5. Sun, S., Bao, E., Pan, Y.: Component feature model for product layout design. Journal of Computer-Aided Design \& Computer Graphics 11, 28-32 (1999) (in Chinese)

6. Zhao, D., He, R.: Brand Styling and Feature Research of Alfa Romeo. Art \& Design 219, 72-74 (2011) (in Chinese)

7. Hu, W., Zhao, J., Zhao, D.: Study on Styling Image of Vehicle Based on Form Feature Lines. China Mechanical Engineering 20, 496-500 (2009) (in Chinese)

8. Van Someren, M.W.: The Think Aloud Method: A Practical Guide to Modeling Cognitive Processes. The Academic Press, London (1994) (in Chinese)

9. Tan, H., Zhao, J., Zhao, D.: Construction and Application of the Quantitative Model of Automobile Form Features. Journal of Hunan University (Natural Sciences) 36, 27-31 (2009) (in Chinese)

10. Zhu, Y.: Semantic Study on Automobile Form and Design Process Configuration. Hunan University, ChangSha (2009) 